\title{
IGNORING PUBLIC HEALTH ENGLAND REPORT ON SUGAR REDUCTION WOULD BE RECKLESS
}

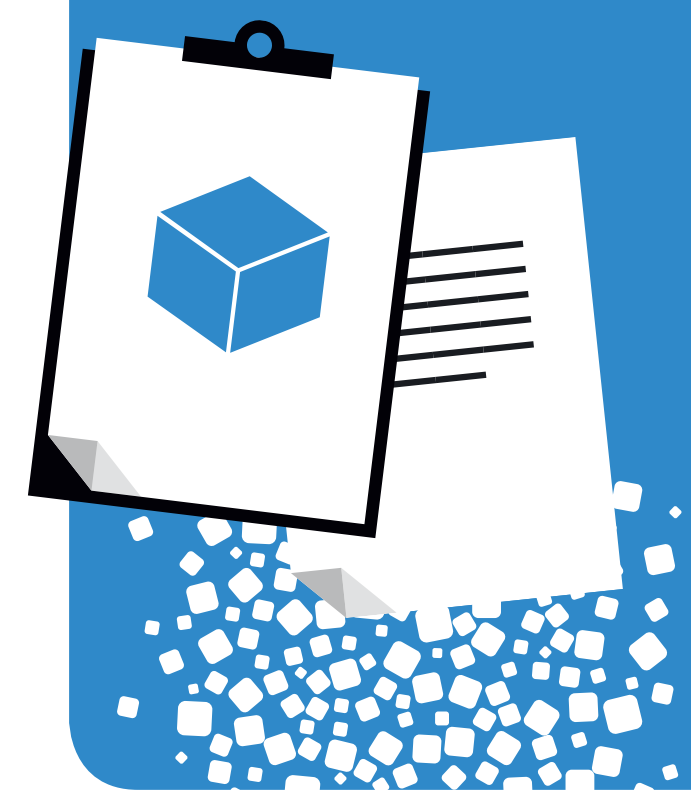

The British Society of Dental Hygiene and Therapy (BSDHT) fully support the new recommendations on sugar published by Public Health England (PHE) and believe ignoring them will lead to thousands more children needlessly suffering from poor oral health.

The eagerly anticipated evidencebased, report from PHE $^{1}$ recognised the need for high level intervention on sugar and identified a number of key areas for action including banning price promotions and the introduction of a $10-20 \%$ tax on sugary soft drinks.

Michaela ONeill, President of the BSDHT, responded to the report: 'This report confirms what we have known for

\section{EASING THE DENTAL FEARS OF ADULTS AND CHILDREN WITH COMPLEX NEEDS}

A dentist from the Central and North West London Trust has put together an illustrated story booklet that describes a patient journey for children and adults with complex needs and about to undergo major surgery.

Senior Dental Officer, Kirsten Criggie, 30, developed it to help ease the fears of a child with complex needs who is set to have an operation, as well as the parents, by explaining the process in easy to understand terms.

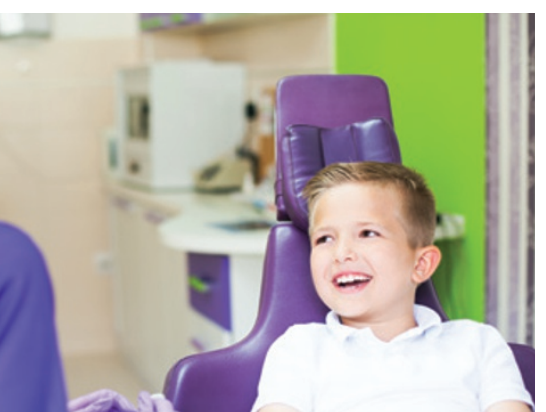

Kirsten, who is part of the Buckinghamshire Priority Dental Service, said: 'We identified the need for this resource when the patient's mother was concerned about her daughter going through the process. They used story boards at school so we thought we could develop one so the process wouldn't be such a big surprise'

Thought to be the first of its type in dentistry, though not in hospitals, the story board has interested some of her colleagues so she has now adapted it to make it more general to help paediatric patients going for a dental general anaesthetic. It is also currently under development for the special care adult dentistry general anaesthetic pathway. Colleagues in other specialities have also expressed interest.

'We've had a fantastic response. We've shown it to a few children with autistic spectrum conditions and asked them if they would find it helpful and help them to prepare for a procedure and they said yes.

'It's also helpful for parents because a lot of them are anxious. So if they know what's going to happen that should make them less anxious and mean the child is less anxious as well', she said.

Buckinghamshire Priority Dental Service offers special care dentistry for people in Milton Keynes who are unable to access a general dental practitioner and need dental treatment.

The service is for adults and children living in the Hertfordshire and South Midlands and Thames Valley catchment areas who have learning disabilities, complex medical needs, or severe mental health problems. It is also for children with severe behavioural management problems and adults with very severe anxiety and dental phobias.

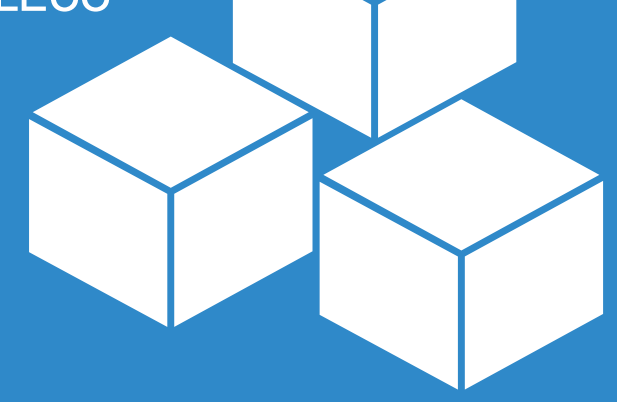

a long time; we need to act now on our nation's addiction to sugar and stop children suffering from potentially painful and distressing oral health problems.

'Shockingly, a recent study found half of eight year olds have visible signs of decay on their teeth and a third of children are starting school with visible signs of tooth decay.

'Children's tooth extractions cost the NHS around $£ 30$ million per year with the key cause being tooth decay.

'The BSDHT and our members have long campaigned for action on sugar and these recommendations need to be seriously reviewed and acted upon; the evidence is all there and ignoring them would simply be reckless.

'The BSDHT continue to strive to improve children's oral health though education within dental practices and schools with our First Smiles initiative. But the government needs to act on this report and support the dental industry if we are to really help future generations of children benefit from healthier diets and also allow parents to understand how destructive too much sugar can be to their oral health.'

1. Public Health England. Sugar reduction: from evidence to into action (2015). Available online at www.gov. uk/government/publications/sugarreduction-from-evidence-into-action

\section{And the winner is...}

Congratulations to Dr Sualeh Khan, the winner of the BDJ Team CPD prize draw. An Apple Watch is on its way to you! 